\title{
PARAMETRIC OPTIMIZATION OF CENTRIFUGAL-MAGNETIC FORCE ASSISTED ABRASIVE FLOW MACHINING PROCESS USING UTILITY CONCEPT
}

\author{
Ramandeep Singh ${ }^{1}$, R.S. Walia ${ }^{2}$, N.M. Suri ${ }^{3}$ \\ ${ }^{1}$ Research Scholar (Production Engg.), PEC University of Technology, Chandigarh, Punjab, \\ Indiaramandeep_1975@rediffmail.com \\ ${ }^{2}$ Associate Prof.(Mechanical Engg.), DTU, Delhi, India \\ ${ }^{3}$ Prof.(Production Engg.), PEC University of Technology, Chandigarh, Punjab, India Corresponding Author
}

\begin{abstract}
:
The traditional Taguchi method is widely used for optimizing the process parameters of a single response problem. Optimization of a single response results the non-optimum values for remaining. But, the performance of a machining process is often evaluated by several quality responses. Under such circumstances, multi-characteristics response optimization may be the solution to optimize multi-responses simultaneously. In the present work, a multicharacteristics response optimization model based on Taguchi and Utility concept is used to optimize process parameters, such as magnetic flux, rotational speed of CFG rod, shape of CFG rod, number of cycles, abrasive-toiron ratio and abrasive particle size on multiple performance characteristics, namely, surface roughness $\left(R_{a}\right)$ and material removal (MR) during polishing of hollow cylindrical brass work-pieces with Centrifugal-Magnetic Force Assisted Abrasive Flow Machining $\left(C M A^{2} F M\right)$ Process. Taguchi's $L_{27}$ orthogonal array $(O A)$ is selected for experimental planning. The ANOVA and F-tests are used to analyze the results. It is found that all the input parameters significantly improve the Utility function comprising of two quality characteristics (MR and $\% \Delta R_{a}$ ). Further, the confirmation tests are conducted and the results are found to be within the confidence interval.
\end{abstract}

Keywords: Abrasive Flow Machining (AFM), Centrifugal Force, Magnetic Force, CFG Rod, CMA ${ }^{2} F M$, Utility Concept,TaguchiMethod,MultiResponseOptimization

\section{INTRODUCTION}

The abrasive flow machining (AFM) is a polishing process based on the flow of a pressurized abrasive media through the work-piece. The rheological properties of the media like easy flow-ability, better self deformability and abrading very finely helps to get better surface conditions and sufficiently closer tolerances [9]. The AFM is suitable for finishing external as well as internal surfaces, which are complex and out of reach. Although the AFM is gaining importance due to its high-accuracy and high-efficiency in finishing the materials, but it has a limitation of longer cycle time to achieving required surface finish [11]. To improve the capability of the process, in the present paper, the AFM is hybridized by applying additional centrifugal and magnetic force applied to abrasive laden media and the new process is termed as Centrifugal-Magnetic Force Assisted Abrasive Flow Machining $\left(\mathrm{CMA}^{2} \mathrm{FM}\right)$ Process. For the optimization of $\mathrm{CMA}^{2} \mathrm{FM}$ process parameters, more than one quality characteristics have to be simultaneously optimized. Therefore, in the situations involving many measurable response characteristics of a process, an optimization strategy is required that can provide a unified criterion to represent the overall optimal setting of process parameters with respect to all the responses. These types of optimization problems need to be handled by multi-response optimization techniques. In the past, the applications of Taguchi method and Response Surface Methodology (RSM) have mainly dealt with single response problems $[2,6,7,10]$ and only very few applications are reported for multiresponse problems [1,16]. Shiau [13] solved the multiresponse problem by assigning the weights to $\mathrm{S} / \mathrm{N}$ ratio of each quality characteristic and then summing up the weighted $\mathrm{S} / \mathrm{N}$ ratios for the measurement of overall performance of a process. Tai et al. [17] used empirical loss functions for evaluating multi response problem by involving six parameters and nine responses for the surface mount process. Singh [14] studied the optimization of the quality characteristics of Magnetically Assisted Abrasive Flow Machining (MAAFM) process by using multiresponse optimization through utility concept and Taguchi method. Walia et al. [18] studied Multi-response optimization of centrifugal Force Assisted Abrasive Flow Machining (CFAAFM) process through Taguchi method and Utility Concept. Goyal et al. [5] studied optimization of low-pressure cold sprayed coatings process parameter using Taguchi multi-response. Singh et al. [15] studied the parametric optimization of Hybrid Electric Discharge 
Machining process with continuous and discontinuous ultrasonic vibrations on work piece. Based on the foregoing discussions, in this paper, Taguchi approach and utility concept has been used for the multi-response optimization.

2.CENTRIFUGAL-MAGNETIC

FORCE

\section{ASSISTED ABRASIVE FLOW MACHINING (CMA ${ }^{2}$ FM) PROCESS}

The $\mathrm{CMA}^{2} \mathrm{FM}$ process (as shown in figure 1) is the enhancement of conventional AFM by the addition of centrifugal and magnetic force to the pressurized abrasive media flowing through the work-piece. A three part fixture was designed and developed to accommodate the work piece and the attachments to provide the additional centrifugal and magnetic forces. The abrasive media was passed through the central hole in the work-piece during the operation. The Centrifugal Force Generator (CFG) rod was retained axially with the help of rotation attachment in such a way that there was no hindrance in the media flow and sealing. The rotary motion of CFG rod imparts centrifugal force to the abrasives laden media. The magnetic force through the entire work piece length was provided by specially designed attachment, which was placed in central part of fixture. Consequentially the abrasive particles were pulled, normal to the axis, towards the internal surface of the work piece. Due to this the media was subjected to additional centrifugal and magnetic force along with the extrusion pressure.

\section{PROCESS PARAMETERS OF CMA ${ }^{2}$ FM}

The six process parameters chosen for this study were: Magnetic Flux (M); Rotational Speed of CFG Rod (S);
Shape of CFG Rod (C); Number of Cycles (N); Abrasive-toIron Ratio (R); Abrasive Particle Size (G). The selected process parameters and their levels are given in Table 1. Each parameter was analyzed at three levels.

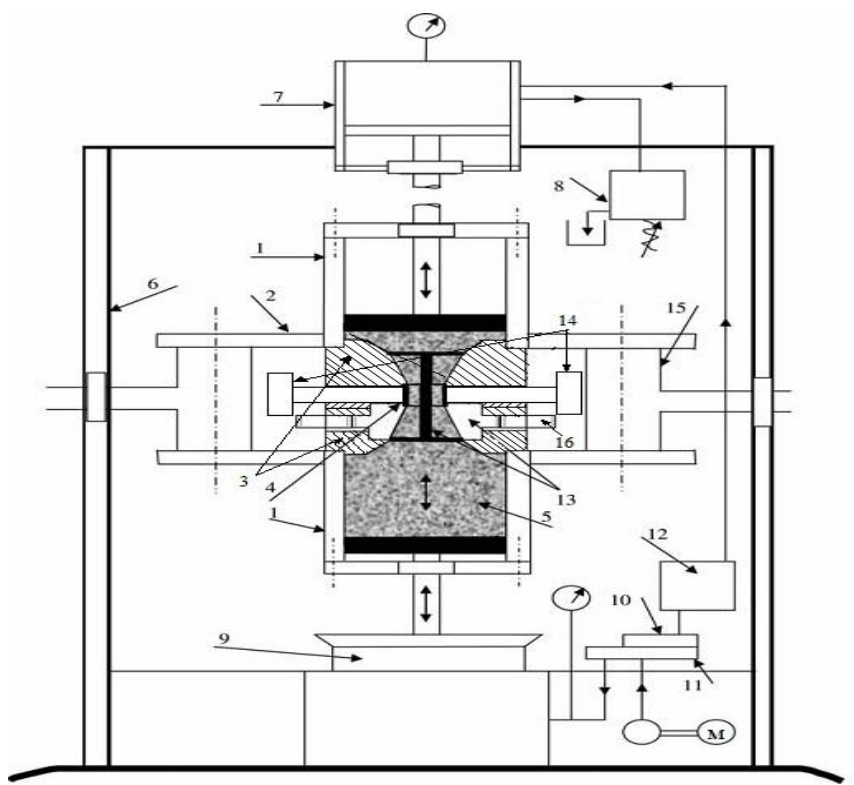

Figure 1. Schematic Diagram of $\mathrm{CMA}^{2} \mathrm{FM}$.

Setup:1Cylinder containing media; 2. Flange; 3.Fixture; 4.Work piece; 5. Abrasive laden media; 6. Hydraulic press; 7. Auxiliary cylinder; 8. Modular relief valve; 9. Piston of hydraulic press; 10. Directional control valve; 11 and12. Manifold blocks; 13. Rotating CFG rod assembly; 14. Electromagnet; 15. Eye bolt; and16.Idlegear

Table 1. Process Parameters and their Values at Different Levels

\begin{tabular}{|l|l|l|l|l|l|}
\hline Symbol & Process Parameters & Unit & Level 1 & Level 2 & Level 3 \\
\hline M & Magnetic Force & Tesla & 0 & 0.3 & 0.6 \\
\hline S & Rotational speed of the rod & RPM & 0 & 30 & 60 \\
\hline C & Shape of CFG rod & Nil & Triangular(T) & Rectangular(R) & Spline(S) \\
\hline N & Number of Cycles & Number & 2 & 4 & 6 \\
\hline G & Abrasive particle size & Mesh Size & 100 & 150 & 200 \\
\hline R & $\mathrm{Al}_{2} \mathrm{O}_{3}$-to- Fe Ratio & Ratio & $2: 1$ & $3: 2$ & $1: 1$ \\
\hline
\end{tabular}

Polymer-to-Gel Ratio: 1:1, Work-piece material: Brass, Abrasive type: $\mathrm{Al}_{2} \mathrm{O}_{3}$, Fe particle size: 300 mesh size, Extrusion Pressure: 5N $\backslash \mathrm{mm}^{2}$, Media Flow Volume: $290 \mathrm{~cm}^{3}$, Reduction Ration: 0.98, Temperature: $32 \pm 2^{\circ} \mathrm{C}$, Initial Surface Roughness of Work-piece: 1.2 - 1.9 micron, Media Viscosity: 810 Pa.s

\section{UTILITY CONCEPT}

A product or a process is normally evaluated on the basis of certain number of quality characteristics, sometimes

conflicting in nature. Therefore, a combined measure is necessary to gauge its overall performance, which must take into account the relative contribution of all the quality characteristics. Such a combined measure represents the overall utility of a process. The overall utility of a process/product can be represented as the usefulness of a product or a process in reference to the expectations of the

users. In this paper, Utility of $\mathrm{CMA}^{2} \mathrm{FM}$ process has been considered as the sum of the individual utilities of various quality characteristics of the process.

Thus, if $X_{i}$ is the measure of effectiveness of an attribute (or quality characteristic) $i$ and there are $n$ attributes evaluating the outcome space, then the joint Utility function can be expressed [3] as: 
$\mathrm{U}\left(\mathrm{X}_{1}, \mathrm{X}_{2}, \ldots . . \mathrm{X}_{\mathrm{n}}\right)=$

$\mathrm{f}\left(\mathrm{U}_{1}\left(\mathrm{X}_{1}\right), \mathrm{U}_{2}\left(\mathrm{X}_{2}\right), \ldots \ldots \mathrm{U}_{\mathrm{n}}\left(\mathrm{X}_{\mathrm{n}}\right)\right)$

where $\mathrm{U}_{\mathrm{i}}\left(\mathrm{X}_{\mathrm{i}}\right)$ is the utility of the $i^{\text {th }}$ attribute.

The overall Utility function is the sum of individual utilities if the attributes are independent, and is given as:

$$
\mathrm{U}\left(\mathrm{X}_{1}, \mathrm{X}_{2}, \ldots \mathrm{X}_{\mathrm{n}}\right)=\sum_{\mathrm{i}=1}^{\mathrm{n}} \mathrm{U}_{\mathrm{i}}\left(\mathrm{X}_{\mathrm{i}}\right)
$$

The attributes may be assigned weights depending upon the relative importance or priorities of the characteristics. The overall utility function after assigning weights to the attributes can be expressed as:

$$
\mathrm{U}\left(\mathrm{X}_{1}, \mathrm{X}_{2}, \ldots \mathrm{X}_{\mathrm{n}}\right)=\sum_{\mathrm{i}=1}^{\mathrm{n}} \mathrm{W}_{\mathrm{i}} \mathrm{U}_{\mathrm{i}}\left(\mathrm{X}_{\mathrm{i}}\right)
$$

where $\mathrm{W}_{\mathrm{i}}$ is the weight assigned to the attribute $i$, the sum of the weights for all the attributes must be equal to one.

\subsection{Determination Of Utility Value}

A preference scale for each quality characteristic is constructed for determining its utility value. Two arbitrary numerical values (preference number) 0 and 9 are assigned to the just acceptable and the best value of the quality characteristic respectively. The preference number $\left(P_{i}\right)$ can be expressed on a logarithmic scale as follow $[4,8]$ :

$$
P_{i}=A \times \log \left(\frac{X_{i}}{X_{i}^{\prime}}\right)
$$

where $X_{i}=$ value of any quality characteristic or attribute $i$; $X_{i}^{\prime}=$ just acceptable value of quality characteristic or attribute $i$; and $\mathrm{A}=$ constant. The value of $A$ can be found by the condition that if $X_{\mathrm{i}}=X^{*}$ (where $X^{*}$ is the optimal or best value), then $P_{i}=9$

Therefore, $A=\frac{9}{\log \frac{X^{*}}{X_{i}^{\prime}}}$

The overall utility can be calculated as:

$\mathrm{U}=\sum_{\mathrm{i}=1}^{\mathrm{n}} \mathrm{W}_{\mathrm{i}} \mathrm{P}_{\mathrm{i}}$

subject to the condition: $\sum_{\mathrm{i}=1}^{\mathrm{n}} \mathrm{W}_{\mathrm{i}}=1$
Taguchi suggested that, Utility function "higher the better type" would be better. Therefore, if the Utility function is maximized, the quality characteristics considered for its evaluation will automatically be optimized (maximized or minimized as the case may be).

\subsection{The Multi-Characteristic Optimization}

\section{Algorithm}

The following stepwise procedure for carrying out multiresponse optimization with Utility concept and Taguchi method was used.

- The optimal values of the selected performance characteristics had been found separately by using Taguchi's parameter design approach.

- Using the optimal values and the minimum levels, preference scales for each performance characteristic had been constructed. (Using Eq. (4))

- Weights $W_{i}, i=1,2, \ldots ., n$, were assigned to various output characteristics based on experience and the application of the component such that the sum of weights is equal to 1 .

- Using Eq. (6), the utility values for each experiment against each trial condition of the experiment had been found.

- The obtained utility values in step 4 were used as a response of the trial conditions of the selected experimental plan.

- The results were analyzed using procedure suggested by Taguchi.

- The optimal settings of the process parameters for optimum utility (mean and minimum deviation around the mean) had been found.

- After considering the optimal significant parameters as determined in step 7, the individual characteristic values were predicted.

- Number of confirmation experiments had been conducted at the optimal setting and results were compared with the predicted optimal values.

\section{MULTI-RESPONSE OPTIMIZATION FOR CMA $^{2}$ FM RESPONSE PARAMETERS}

Taguchi $\mathrm{L}_{27}$ orthogonal array (OA) [12] had been adopted for conducting the experiments. To obtain the optimal settings of the process, response parameters selected were percentage improvement in surface roughness $\left(\% \Delta \mathrm{R}_{\mathrm{a}}\right)$, and material removal (MR). When they were optimized individually, the summary of results produced was as per Table 2.

Table 2. Optimal Setting and Values of Process Parameters (Individual Quality Characteristic Optimization)

\begin{tabular}{|l|l|l|l|}
\hline $\begin{array}{l}\text { Response } \\
\text { Characteristic }\end{array}$ & $\begin{array}{l}\text { Optimal Process } \\
\text { Parameters }\end{array}$ & $\begin{array}{l}\text { Significant process } \\
\text { parameters }\end{array}$ & $\begin{array}{l}\text { Predicted optimal } \\
\text { value of quality } \\
\text { characteristics }\end{array}$ \\
\hline Material Removal MR & $\mathrm{M}_{2} \mathrm{~S}_{3} \mathrm{C}_{3} \mathrm{~N}_{3} \mathrm{G}_{3} \mathrm{R}_{1}$ & $\mathrm{M}, \mathrm{S}, \mathrm{C}, \mathrm{N}, \mathrm{G}, \mathrm{R}$ & $12.24 \mathrm{mg}$ \\
\hline $\begin{array}{l}\% \text { Improvement in } \mathrm{R} \\
\left(\% \Delta \mathrm{R}_{\mathrm{a}}\right)\end{array}$ & $\mathrm{M}_{2} \mathrm{~S}_{2} \mathrm{C}_{1} \mathrm{~N}_{3} \mathrm{G}_{2} \mathrm{R}_{2}$ & $\mathrm{M}, \mathrm{S}, \mathrm{C}, \mathrm{N}, \mathrm{G}, \mathrm{R}$ & $53.65 \%$ \\
\hline
\end{tabular}


Following is the stepwise procedure for transforming experimental data into utility data.

\subsection{Construction Of Preference Scales}

$\square$ Preference scale for $\mathrm{MR}\left(\mathrm{P}_{\mathrm{MR}}\right)$ :

$\mathrm{X}^{*}=$ Optimal value of MR $=12.24$ (Table 2$)$

$\mathrm{X}_{\mathrm{i}}^{\prime}=$ Just acceptable value of MR $=4$ (All the observed values of MR are greater than 4)

Following relation is obtained from Equation 4:

$$
\mathrm{P}_{\mathrm{MR}}=18.52 \times \log \left(\frac{\mathrm{X}_{\mathrm{MR}}}{5}\right)
$$

$\square$ Preference scale for $\Delta \mathrm{R}_{\mathrm{a}}\left(\mathrm{P}_{\Delta \mathrm{Ra}}\right)$ :

$\mathrm{X}^{*}=$ Optimal value of $\Delta \mathrm{R}_{\mathrm{a}}=53.65$ ( Table 2)

$\mathrm{X}_{\mathrm{i}}^{\prime}=$ Just acceptable value of $\Delta \mathrm{R}_{\mathrm{a}}=5$ (All the observed values of $\Delta R_{a}$, are greater than 5)

Following relation is obtained from Equation 4:

$$
\mathrm{P}_{\Delta \mathrm{Ra}}=8.73 \times \log \left(\frac{\mathrm{X}_{\Delta \mathrm{Ra}}}{5}\right)
$$

\subsection{Calculation of Utility Value}

Equal weights (1/2 each) had been assigned to the selected responses. The following relation was used to calculate the utility based upon the all experimental trials:

$$
\begin{aligned}
U(n, r)=P_{M R}(n . r) & \times W_{M R} \\
& +P_{\Delta R a}(n, r) \times W_{\Delta R a}
\end{aligned}
$$

where $\mathrm{W}_{\mathrm{MR}}=\frac{1}{2} ; \quad \mathrm{W}_{\Delta \mathrm{Ra}}=\frac{1}{2} ; \quad n$ is the trial number (n $=1,2,3, \ldots \ldots, 27)$ and $r$ is the repetition number $(r=1,2,3)$.

\begin{tabular}{|c|c|c|c|c|}
\hline \multirow{2}{*}{$\begin{array}{l}\text { Trial } \\
\text { Number }\end{array}$} & \multicolumn{3}{|c|}{ Utility Values } & \multirow{2}{*}{$\begin{array}{l}\text { S/N Ratio } \\
\text { (db) }\end{array}$} \\
\hline & R1 & $\mathbf{R 2}$ & $\mathbf{R 3}$ & \\
\hline 1 & 11.29 & 11.42 & 11.47 & 21.13 \\
\hline 2 & 10.58 & 10.55 & 10.43 & 20.44 \\
\hline 3 & 11.04 & 10.51 & 10.87 & 20.67 \\
\hline 4 & 11.47 & 11.32 & 11.26 & 21.09 \\
\hline 5 & 10.96 & 10.97 & 10.65 & 20.71 \\
\hline 6 & 10.13 & 9.82 & 10.01 & 19.98 \\
\hline 7 & 10.75 & 11.45 & 11.36 & 20.96 \\
\hline 8 & 10.30 & 10.05 & 10.00 & 20.10 \\
\hline 9 & 11.66 & 11.49 & 10.96 & 21.10 \\
\hline 10 & 10.94 & 11.14 & 11.27 & 20.91 \\
\hline 11 & 11.19 & 11.05 & 10.74 & 20.81 \\
\hline 12 & 10.31 & 9.99 & 10.21 & 20.14 \\
\hline 13 & 11.32 & 11.52 & 11.63 & 21.20 \\
\hline 14 & 11.65 & 11.66 & 11.72 & 21.34 \\
\hline 15 & 11.13 & 10.68 & 10.85 & 20.73 \\
\hline 16 & 11.42 & 11.37 & 11.45 & 21.14 \\
\hline 17 & 12.19 & 12.77 & 12.13 & 21.84 \\
\hline 18 & 11.57 & 11.60 & 11.65 & 21.29 \\
\hline 19 & 11.41 & 11.35 & 11.56 & 21.17 \\
\hline 20 & 11.32 & 11.39 & 11.55 & 21.15 \\
\hline 21 & 10.57 & 10.46 & 10.10 & 20.32 \\
\hline 22 & 11.37 & 11.30 & 11.22 & 21.06 \\
\hline 23 & 11.59 & 11.68 & 11.66 & 21.32 \\
\hline
\end{tabular}
The calculated Utility values are shown in Table 3 .

Table 3. Calculated Utility data Base on Responses MR and $\Delta \mathrm{R}_{\mathrm{a}}$

\begin{tabular}{|l|l|l|l|l|}
\hline 24 & 10.52 & 10.52 & 10.90 & 20.54 \\
\hline 25 & 10.60 & 10.88 & 11.15 & 20.73 \\
\hline 26 & 11.35 & 11.06 & 11.59 & 21.08 \\
\hline 27 & 11.42 & 11.03 & 11.51 & 21.07 \\
\hline $\begin{array}{l}\mathrm{R}_{1}, \mathrm{R}_{2}, \mathrm{R}_{3}=\text { repetitions of experiments against each of } \\
\text { the trial conditions }\end{array}$ \\
\hline
\end{tabular}

\subsection{Analysis Of Utility Data For Optimal Setting Of}

\section{Process Parameters}

The average and main response in terms of Utility values based upon two response characteristics (MR and $\left.\Delta R_{a}\right)$ and $\mathrm{S} / \mathrm{N}$ ratio (refer Table 3 and 4 ) are plotted in Figure 2. It can be observed from Figure 2 that the $2^{\text {nd }}$ level of Magnetic Flux $\left(\mathrm{M}_{2}\right)$, the $3^{\text {rd }}$ level of Rotational Speed of CFG Rod $\left(\mathrm{S}_{3}\right)$, the $1^{\text {st }}$ level of Shape of CFG Rod $\left(\mathrm{C}_{1}\right)$, the $2^{\text {nd }}$ level of Number of Cycles $\left(\mathrm{N}_{2}\right)$, the $1^{\text {st }}$ level of Abrasive-to-Iron Ratio $\left(R_{1}\right)$ and the $3^{\text {rd }}$ level of Abrasive Particle Size $\left(G_{3}\right)$ are expected to yield a maximum valve of the Utility and $\mathrm{S} / \mathrm{N}$ ratio within the experimental space.

The pooled version of ANOVA for the Utility data and S/N ratio are given in Table 5 and 6 respectively. It can be noted from the Table 5 that all the response parameters have significant effect (at 95\% confidence level) on the Utility function. The shape of CFG rod is the dominant parameter affecting the Utility function followed by magnetic flux and rotational speed of CFG rod and abrasive to iron ratio.

\subsection{Optimal Values Of Response Characteristics (Predicted Means)}

The average values of all the quality characteristics at the optimum levels of significant parameters are recorded in Table 8 . The optimal values of the predicted means $(\mu)$ of different response characteristics can be obtained from equation:

$\mu=\mathrm{M}_{2}+\mathrm{S}_{3}+\mathrm{C}_{1}+\mathrm{N}_{2}+\mathrm{G}_{3}+\mathrm{R}_{1}-5 \mathrm{~T}$

where, $\mathrm{M}_{2}-$ Second level of Magnetic Flux; $\mathrm{S}_{3}-$ Third level of Rotational Speed of CFG Rod; $\mathrm{C}_{1}-$ First level of Shape of CFG Rod; $\mathrm{N}_{2}-$ Second level of Number of Cycles; $\mathrm{G}_{3}-$ First level of Abrasive Particle Size; $\mathrm{R}_{1}$ - Third level of Abrasive-to-Iron Ratio.

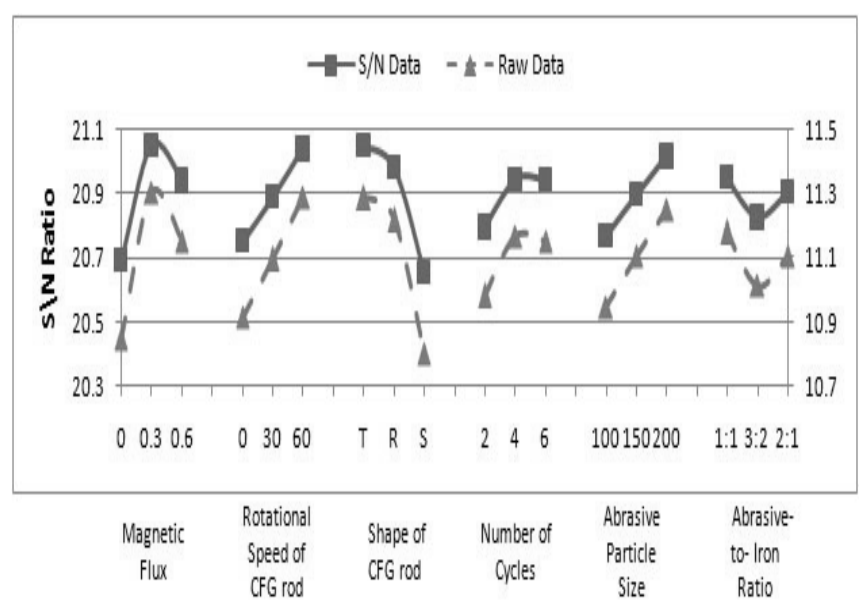

Figure 2 The Main Effects in Terms of Utility Values for $\mathrm{S} / \mathrm{N}$ ratioandRawDat 
Table 4. Average Values and Main Effects (Raw Data: MR and $\Delta \mathrm{R}_{\mathrm{a}}$ )

\begin{tabular}{|l|l|l|l|l|l|l|l|}
\hline \multirow{2}{*}{$\begin{array}{l}\boldsymbol{L} \\
\downarrow\end{array}$} & $\mathbf{M}$ & $\mathbf{S}$ & $\mathbf{C}$ & $\mathbf{N}$ & $\mathbf{G}$ & $\mathbf{R}$ \\
\hline \multirow{2}{*}{$\begin{array}{l}\text { Average } \\
\text { Utility } \\
\text { Values }\end{array}$} & $\mathbf{L}_{\mathbf{1}}$ & 10.85 & 10.92 & 11.29 & 10.98 & 10.95 & 11.18 \\
\cline { 2 - 8 } & $\mathbf{L}_{\mathbf{2}}$ & 11.30 & 11.10 & 11.22 & 11.17 & 11.11 & 11.01 \\
\hline \multirow{2}{*}{$\begin{array}{l}\text { Main } \\
\text { Effects }\end{array}$} & $\mathbf{L}_{\mathbf{3}}-\mathbf{L}_{\mathbf{1}}$ & 0.46 & 0.18 & -0.07 & 0.19 & 0.16 & -0.17 \\
\cline { 2 - 8 } & $\mathbf{L}_{\mathbf{3}}-\mathbf{L}_{\mathbf{2}}$ & -0.15 & 0.20 & -0.42 & -0.02 & 0.15 & 0.10 \\
\hline \multirow{2}{*}{ Difference } & $\begin{array}{l}{\left[\left(\mathbf{L}_{3}-\mathbf{L}_{\mathbf{2}}\right)-\left(\mathbf{L}_{\mathbf{2}^{-}}\right.\right.} \\
\left.\left.\mathbf{L}_{\mathbf{1}}\right)\right]\end{array}$ & -0.61 & 0.02 & -0.35 & -0.20 & -0.01 & 0.26 \\
\hline
\end{tabular}

$\mathrm{L}_{1}, \mathrm{~L}_{2}$ and $\mathrm{L}_{3}$ represent levels 1,2 and 3 respectively of parameters. $\mathrm{L}_{2}-\mathrm{L}_{1}$ is the average main effect when the corresponding parameter changes from level 1 to level 2. $\mathrm{L}_{3}-\mathrm{L}_{2}$ is the main effect when the corresponding parameter changes from level 2 to level 3. M- Magnetic Flux, S- Rotational Speed of CFG Rod, C- Shape of CFG rod, N- Number of Cycles, G- Abrasive Particle Size, R- Ratio of Abrasive to Iron

Table 5. Pooled ANOVA (Raw Data: $M R$ and $\Delta R_{a}$ )

\begin{tabular}{|l|l|l|l|l|l|l|}
\hline Source & SS & DOF & V & F-Ratio & SS $^{\prime}$ & P \% \\
\hline M & 2.95 & 2 & 1.47 & 35.68 & 2.87 & 11.27 \\
\hline S & 1.88 & 2 & 0.94 & 22.75 & 1.80 & 7.07 \\
\hline C & 3.75 & 2 & 1.88 & 45.49 & 3.68 & 14.46 \\
\hline N & 0.59 & 2 & 0.30 & 7.23 & 0.52 & 2.03 \\
\hline G & 1.29 & 2 & 0.65 & 15.63 & 1.21 & 4.76 \\
\hline R & 0.37 & 2 & 0.19 & 4.54 & 0.29 & 1.16 \\
\hline E (Pooled) & 14.55 & 68 & 3.10 & - & 15.07 & 59.25 \\
\hline Total (T) & 25.4 & 26 & - & - & 25.4 & 100.00 \\
\hline
\end{tabular}

* Significant at $95 \%$ confidence level, SS - Sum of Squares, DOF - Degree of Freedom, V - Variance, SS' - Pure Sum of Squares

Table 6. Average Values and Main Effects (S/N Data: MR and $\Delta \mathbf{R}_{\mathrm{a}}$ )

\begin{tabular}{|c|c|c|c|c|c|c|c|}
\hline \multicolumn{2}{|c|}{$\begin{array}{l}\longrightarrow \text { Process Parameter } \\
\downarrow_{\text {Level }}\end{array}$} & $\mathbf{M}$ & $\mathbf{S}$ & $\mathbf{C}$ & $\mathbf{N}$ & $\mathbf{G}$ & $\mathbf{R}$ \\
\hline \multirow{3}{*}{$\begin{array}{l}\text { Average } \\
\text { Utility } \\
\text { Values }\end{array}$} & $\mathbf{L}_{1}$ & 20.69 & 20.75 & 21.05 & 20.79 & 20.77 & 20.95 \\
\hline & $\mathbf{L}_{2}$ & 21.05 & 20.89 & 20.98 & 20.94 & 20.9 & 20.82 \\
\hline & $\mathbf{L}_{3}$ & 20.94 & 21.04 & 20.65 & 20.94 & 21.02 & 20.90 \\
\hline \multirow{2}{*}{$\begin{array}{l}\text { Main } \\
\text { Effects }\end{array}$} & $\mathbf{L}_{2}-\mathbf{L}_{1}$ & 0.36 & 0.14 & -0.07 & 0.15 & 0.13 & -0.13 \\
\hline & $\mathbf{L}_{3}-\mathbf{L}_{2}$ & -0.11 & 0.15 & -0.33 & -0.004 & 0.12 & 0.08 \\
\hline Difference & $\begin{array}{l}{\left[\left(\mathbf{L}_{3}-\mathbf{L}_{2}\right)-\left(\mathbf{L}_{2}-\right.\right.} \\
\left.\left.\mathbf{L}_{1}\right)\right]\end{array}$ & -0.47 & 0.01 & -0.26 & -0.15 & -0.01 & 0.21 \\
\hline
\end{tabular}

$\mathrm{L}_{1}, \mathrm{~L}_{2}$ and $\mathrm{L}_{3}$ represent levels 1,2 and 3 respectively of parameters. $\mathrm{L}_{2}-\mathrm{L}_{1}$ is the average main effect when the corresponding parameter changes from level 1 to level $2 . \mathrm{L}_{3}-\mathrm{L}_{2}$ is the main effect when the corresponding parameter changes from level 2 to level 3. M- Magnetic Flux, S- Rotational Speed of CFG Rod, C- Shape of CFG rod, N- Number of Cycles, G- Abrasive Particle Size, R- Ratio of Abrasive to Iron

Table 7 Pooled ANOVA (S/N Data: MR and $\left.\Delta \mathbf{R}_{\mathrm{a}}\right)$

\begin{tabular}{|l|l|l|l|l|l|l|}
\hline Source & SS & DOF & $\mathbf{V}$ & F-Ratio & SS' $^{\prime}$ & P \% \\
\hline $\mathrm{M}$ & 0.61 & 2 & 0.30 & 99.81 & 0.60 & 12.53 \\
\hline S & 0.37 & 2 & 0.18 & 60.32 & 0.36 & 7.52 \\
\hline $\mathrm{C}$ & 0.80 & 2 & 0.40 & 131.63 & 0.79 & 16.56 \\
\hline $\mathrm{N}$ & 0.13 & 2 & 0.07 & 21.51 & 0.12 & 2.60 \\
\hline $\mathrm{G}$ & 0.27 & 2 & 0.14 & 45.23 & 0.27 & 5.61 \\
\hline $\mathrm{R}$ & 0.07 & 2 & 0.04 & 12.34 & 0.07 & 1.44 \\
\hline E (Pooled) & 2.55 & 14 & 0.64 & - & 2.58 & 53.74 \\
\hline Total (T) & 4.80 & 26 & - & - & 4.80 & 100.00 \\
\hline
\end{tabular}


The 95\% confidence interval of confirmation experiments (CICE) can be computed by using following equation:

$\mathrm{CI}_{\mathrm{CE}}=\sqrt{\mathrm{F}_{\alpha}\left(1, \mathrm{f}_{\mathrm{e}}\right) \mathrm{V}_{\mathrm{e}}\left[\frac{1}{\mathrm{n}_{\mathrm{eff}}}+\frac{1}{\mathrm{R}}\right]}$

where $F_{\alpha}\left(1, f_{e}\right)=$ The F-ratio at the confidence level of $(1-\alpha)$ against DOF 1 and error degree of freedom $f_{e} ; R=$ Sample size for conformation experiments; $\mathrm{V}_{\mathrm{e}}=$ error variance; $\mathrm{n}_{\mathrm{eff}}$ $=\frac{N}{1+D O F} ; \mathrm{N}=$ Total number of Trials $; \mathrm{DOF}=$ Total degree of freedom associated in the estimated of mean response.

Table 8. Average Values of Various Responses at Optimal Levels

\begin{tabular}{|l|l|l|}
\hline Levels & $\begin{array}{l}\text { Material Removal } \\
(\mathbf{M R})\end{array}$ & $\begin{array}{l}\text { Percentage } \\
\text { Improvement on } \mathbf{R}_{\mathbf{a}}\end{array}$ \\
\hline $\mathrm{M}_{2}$ & 9.70 & 49.18 \\
\hline $\mathrm{S}_{3}$ & 10.22 & 47.46 \\
\hline $\mathrm{C}_{1}$ & 9.33 & 49.43 \\
\hline $\mathrm{N}_{2}$ & 9.43 & 48.34 \\
\hline $\mathrm{G}_{3}$ & 10.06 & 47.45 \\
\hline $\mathrm{R}_{1}$ & 10.22 & 46.66 \\
\hline $\begin{array}{l}\text { Note: The above average values are taken from } \\
\text { Experimental Data }\end{array}$ \\
\hline
\end{tabular}

For Material Removal (MR)

$\mu_{\mathrm{MR}}=\mathrm{M}_{2}+\mathrm{S}_{3}+\mathrm{C}_{1}+\mathrm{N}_{2}+\mathrm{G}_{3}+\mathrm{R}_{1}-5 \mathrm{~T}_{\mathrm{MR}}$

$=11.16$

where $\mathrm{M}_{2}=9.70, \mathrm{~S}_{3}=10.22, \mathrm{C}_{1}=9.33, \mathrm{~N}_{2}=9.43, \mathrm{G}_{3}=$ $10.06, \mathrm{R}_{1}=10.22($ Table 8$) ; \mathrm{T}_{\mathrm{MR}}=9.56$
The following values have been obtained by the ANOVA:

$$
\begin{aligned}
& -\quad \mathrm{N}=81, \mathrm{f}_{\mathrm{e}}=56, \mathrm{~V}_{\mathrm{e}}=0.27, \mathrm{n}_{\mathrm{eff}}=3.24, \mathrm{R}=3, \\
& \mathrm{~F}_{0.05}(1,56)=4.016 \\
& -\quad \text { From Equation (12), } \mathrm{CI}_{\mathrm{CE}}= \pm 0.83 \\
& -\quad \text { The predicted optimal range (for confirmation runs }
\end{aligned}
$$
of three experiments) for MR is given by

$$
\mathrm{CI}_{\mathrm{CE}}: 10.33<\mu_{\mathrm{MR}}<11.99
$$

(ii) For Percentage Improvement $\left(\Delta \mathrm{R}_{\mathrm{a}}\right)$

$\mu_{\Delta R a}=M_{2}+S_{3}+C_{1}+N_{2}+G_{3}+R_{1}-5 T_{\Delta R a}$ $=52.47$

where $\mathrm{M}_{2}=49.18, \mathrm{~S}_{3}=47.46, \mathrm{C}_{1}=49.43, \mathrm{~N}_{2}=48.34, \mathrm{G}_{3}=$ $47.45, \mathrm{R}_{1}=46.66$ (Table 8); $\mathrm{T}_{\Delta \mathrm{Ra}}=47.21$

The following values have been obtained by the ANOVA:

- $\mathrm{N}=81, \mathrm{f}_{\mathrm{e}}=56, \mathrm{~V}_{\mathrm{e}}=4.53, \mathrm{n}_{\text {eff }}=3.24, \mathrm{R}=3$, $\mathrm{F}_{0.05}(1,56)=4.016$

- $\quad$ From Equation (12), $\mathrm{CI}_{\mathrm{CE}}= \pm 3.42$

- The predicted optimal range (for confirmation runs of three experiments) for $\Delta \mathrm{R}_{\mathrm{a}}$ is given by

$$
\mathrm{CI}_{\mathrm{CE}}: 49.05<\mu_{\Delta \mathrm{Ra}}<55.89
$$

\section{CONFIRMATION EXPERIMENTS}

For confirmation, three experiments were performed at optimal settings as suggested by Taguchi analysis of Utility data. The overall average of observed values of response characteristics are given in Table 9 . It can be noticed that these values fall well within the $95 \% \mathrm{CI}_{\mathrm{CE}}$ of the optimal range of the respective response characteristics.

Table 9 Predicted Optimal Values, Confidence Interval and Results of Confirmation Experiments

\begin{tabular}{|l|l|l|l|}
\hline Response Characteristic & $\begin{array}{l}\text { Confidence Interval } \\
\mathbf{9 5 \%}\end{array}$ & $\begin{array}{l}\text { Confidence Interval } \\
\mathbf{9 5 \%}\end{array}$ & $\begin{array}{l}\text { Actual Value (Avg of Confirmation } \\
\text { Exp) }\end{array}$ \\
\hline Material Removal (MR) & $11.16 \mathrm{mg}$ & $\begin{array}{l}\mathrm{CI}_{\mathrm{CE}}: 10.33<\mathrm{MR}< \\
11.99\end{array}$ & 11.29 \\
\hline $\begin{array}{l}\text { Percentage Improvement in } \mathrm{R}_{\mathrm{a}} \\
\left(\% \Delta \mathrm{R}_{\mathrm{a}}\right)\end{array}$ & $52.47 \%$ & $\begin{array}{l}\mathrm{CI}_{\mathrm{CE}}: 49.05<\Delta \mathrm{R}_{\mathrm{a}}< \\
55.89\end{array}$ & 53.08 \\
\hline $\mathrm{CI}_{\mathrm{CE}}-$ Confidence interval for the mean of the confirmation experiments \\
\hline
\end{tabular}

\section{CONCLUSIONS}

Based on the experiments performed on a newly developed experimental set-up for $\mathrm{CMA}^{2} \mathrm{FM}$, the following conclusions have been drawn:

- A simplified model based on Taguchi's approach and utility concept is used to determine the optimal setting of the $\mathrm{CMA}^{2} \mathrm{FM}$ process parameters for multicharacteristics. The model is used to predict an optimal setting of the $\mathrm{CMA}^{2} \mathrm{FM}$ parameters to achieve its optimal performance.

- Process Parameters expected to yield a maximum valve of the Utility and $\mathrm{S} / \mathrm{N}$ ratio within the experimental space are: 0.3 Tesla of Magnetic Force; $60 \mathrm{rpm}$ Rotational Speed of CFG Rod; Triangular Shape of CFG Rod; 4 Numbers of process Cycles; 200 mesh Abrasive Particle Grain Size; and 1:1 \% by weight of Abrasive-to-Iron Ratio.
- All the input parameters significantly improve the Utility function comprising of two quality characteristics (Material Removal and Percentage Improvement in $\mathrm{R}_{\mathrm{a}}$ )

- The model could be extended to any number of performance characteristics provided preference scales for the characteristics are available

\section{REFERENCES}

[1]. Antony J., 2000, "Multi-response optimization in industrial experiments using Taguchi quality loss function and principle component analysis", Quality and Reliability Engineering International, vol. 16, pp. 3 - 8 .

[2]. Creese R., Kumar P., 2001, "Effect of fly ash (as an additive to green sand) on the surface roughness of Al7\% Si alloy castings using Taguchi technique", AFS Transations, USA.

[3]. Derek W.B. (1982), Analysis for optimal decisions, John 
Wiley and Sons, New York

[4]. Gupta, V., Murthy, P.N. (1980). An introduction to engineering design methods, Tata McGraw-Hill, New Delhi

[5]. Goyal T., Walia R.S., Sidhu T.S. , 2011, "Low-pressure cold sprayed coatings process parameter optimization using Taguchi multi-response", International Journal of Surface Engineering and Materials Technology, vol. 1, pp. 5-11.

[6]. Kumar P., Barua P.B., Gaindher J.L., 1996 "Quality of Vprocess method through the Taguchi technique", Quality and Reliability Engineering International, vol. 12, pp. $421-427$.

[7]. Kumar P., Creese R., 1999, "Effect of Zircon sand on surface finish of Al-7\% Si alloy V-process castings", AFS Transactions, USA, pp. 95 - 98.

[8]. Kumar P., Barua P.B., Gaindhar J.L., 2000, “Quality optimization (multi-characteristics) through Taguchi's technique and utility concept". Quality and Reliability Engineering International, vol. 16, pp. 475-485

[9]. Loveless T.R., Williams R.E., Rajurkar K.P., 1994, “A study of the effects of abrasive-flow finishing on various machined surfaces", Journal of Materials Processing Technology, vol. 47, pp. 133-151.

[10]. Lee H.T., Yur J.P., 2000, "Characteristic analysis of EDMed surfaces using Taguchi approach", Materials and Manufacturing Processes, vol. 15 (6), pp. 781-806.

[11]. Rhoades L.J., 1985, "Abrasive flow machining and its use". Proceedings of Non Traditional Machining Conference, Cincinnati, OH, December, pp. 111-120

[12]. Roy, R.K. (1990). A primer on the Taguchi methods, Van Nostrand Reinhold, New York.

[13]. Shiau G.H., 1990, "A study of the sintering properties of iron ores using the Taguchi's parameter design", Journal of Chinese Statistical Association vol. 28, pp. 253-275.

[14]. Singh S., 2002, "Studies in metal finishing with magnetically assisted abrasive flow machining”, $\mathrm{PhD}$ thesis IIT Roorkee.

[15]. Singh J., Satsangi P.S., Walia R.S., Singh V.P., 2011, "Parametric Optimization Of Hybrid Electric Discharge Machining Process With Continuous And Discontinuous Ultrasonic Vibrations On Workpiece", International Journal of Materials Science and Engineering, vol. 2(12), pp. $47-53$.

[16]. Su C.T., Tong L.I. , 1997, “Optimizing multi-response problems in the Taguchi method by fuzzy multiple attribute decision making", Quality and Reliability Engineering International, vol. 13, pp. 25 - 34.

[17]. Tai C.Y., Chen T.S., Wu M.C., 1992, "An enhancement of Taguchi method for optimizing SMT processes", Journal of Electronics Manufacturing vol. 2, pp. 91-100.

[18]. Walia R.S., Shan H.S., Kumar P., 2006, "Multi-response optimization of centrifugal force assisted abrasive flow machining (CFAAFM) process through Taguchi method and Utility Concept", Journal of Materials and Manufacturing Processes, vol. 21, pp. $907-914$. 